\title{
A Study on Factors Affecting Consumption of Organic Tea: Evidence from Consumers in Kathmandu Valley
}

\author{
Gaurav Ojha * \\ ojhagaurav84@gmail.com \\ Upama Shakya ** \\ upu.shakya@gmail.com
}

\begin{abstract}
This study examines the factors affecting consumption of organic tea with evidence from organic tea consumers in Kathmandu Valley. In this study, purchase intention for consuming organic tea is the dependent variable, whereas health benefits, environmental concerns, together with taste and price are considered as independent variables. The study has utilized different types of non-probability sampling procedures to locate 50 regular organic tea consumers within Kathmandu valley. Since, the study on purchase intention regarding organic tea product is a relatively new phenomenon, hence this study is exploratory in its orientation. In this study descriptive analysis, together with Chi-Square results and correlation coefficients have been computed to examine nature, direction and significance of the relationship between selected factors and purchase intention for consuming organic tea. Results indicate that purchase intention of customers towards organic tea product is associated with perceived health benefits and environmental concerns. Besides, consumers are willing to pay higher price to consume organic tea when they perceive significant health benefits even with nonpreferable taste of organic tea products. Furthermore, marketing implications of data analysis and findings have been comprehensively elaborated in this study. And, more importantly, in regards to sustainable consumption patterns, as SDG-12 indicates, this study indicates that consumers in Kathmandu Valley are prepared for responsible consumption as they perceive environmental and health benefits in a given product.
\end{abstract}

Keywords: Organic tea, purchase intention, health benefits, environmental concern, SDG-12

\section{Introduction}

Since, organic is a new marketing concept, retailers and marketers find it difficult to attract customers with this new product concept. However, consumers are gradually giving more attention to organic products as a result of its distinguished production method, which is different from the conventional tea products. Besides, these days consumers are not only searching for product with quality and fair price, in addition they are also becoming conscious about health and environmental issues associated with the product they are purchasing.

* Faculty of Post Graduate Research, Sunway International Business School, Maitidevi Marg, Kathmandu.

* MBA Graduate Sunway International Business School, Maitidevi Marg, Kathmandu, Nepal.

NJMSR V. 3 Issue 2 (2019) 
With this as a reference, in the context of Kathmandu valley also many organic producers and retailers have increased their offering of organic products due to the increased demand from the regular customers. Hence, due to the existence of a great deal of consumer interest, it can be assumed that organic tea industry will continue to evolve and eventually cover larger portion of tea market in Kathmandu Valley. Gradually, customers are becoming aware that organic tea brings health benefits in terms of rejuvenating human body, reducing toxic levels and also providing relief from stress that arises from the hustles and bustles of busy life-style. Besides awareness of consumer is positively moderated by health and environment concern regarding their intention to purchase organic products (Asif, Xuhui, Nasiri, \& Ayyub, 2018)

Moreover, the reference for problem formulation in this study has been derived from the market evidence, from organic farms, organic food restaurants, and shops to organic farmer's market for needs and wants for everything organic among consumers has been gradually building up. However, even with this growth, the people who consume organic products are still very less. Despite social media being used to share information, organic tea marketers lack effective marketing mix for organic products even though it is known that they are better and beneficial for the individual, society and community as a whole.

Acknowledging these market realities as a research problem, this study aims to analyze the factors that influence the consumption of organic tea in the context of customers within Kathmandu Valley. After all, the market for organic food has grown continuously over the last few decades, despite the surge of organic food products; there is little research on organic products tea in the context of Kathmandu valley.

Moreover, a study conducted on organic product reveal that consumer perceive them as healthier and environmental friendly (Magnusson, Arvola, Koivisto-Hursti, Aberg, \& Sjoden, 2003) and another study associates Consumers also associate organic food with natural process and care for the environment (Shafie \& Rennie, 2012). Similarly, acknowledging demographic variables, different studies regarding regular consumers of organic food argue that their profile tend to be educated and affluent (Padel \& Foster, 2005; Stobelaar et al, 2006). In addition, consumers are willing to pay higher prices for environmental friendly products to indicate their ecological friendly behavior (Laroche, Bergeron, \& Barbaro-Forleo, 2001).

In addition, this study also acknowledges larger social problem put forward by SDG-12, sustainable development goal which aims to ensure sustainable consumption and production patterns. Therefore, this study explores increasing interest among consumers for organic tea within Kathmandu Valley and aims to discern whether this increasing trend is based on concerns for health and environment. After all, surge of organic market, retailers and shops indicate that consumers within Kathmandu Valley are gradually realizing the importance environmental and social consequences of their consumption matter, hence express greater environmental concern and are also more conscious organic products (Joshi \& Rahman, 2015) Since, organic tea products are without chemical residues, food additives and preservatives, these products also support SDG-3, which aims to ensure healthy lives and promote wellbeing for people at all ages.

This study has reviewed previous studies that have identified various factors affecting 
consumer behavior toward organic tea. However, factors that have been used to study purchase intention regarding organic tea have remained inconsistent and it also tends to be different depending on context, sample size and sampling procedures. Therefore, this study aims to examine actual factors that affect people to consume organic tea in the context of organic market within Kathmandu Valley. Hence, the main purpose is to identify the factors that determine the consumers' consumption pattern towards organic tea and also to support organic producers or marketers to better understand purchasing intention of their consumers when it comes to buying organic tea productions.

\section{Literature Review and Theoretical Framework}

An independent and rational consumer assumes personal control over what to buy and what to consumer. Besides, consumer's purchasing intentions are influenced by various external factors, such as place, time, and labeling. All these external factors may influence the consumers' purchase intention to purchasing organic tea products (Y. Chen, 2011). For example, in any case if a consumer is able to easily identify the organic products labels, then the intention to purchase the organic tea produce would be much higher. In this study, theoretical framework has been developed from the perspective of theory of planned behavior. This theory indicates that consumer's intention to perform a particular behavior is driven by their attitude, subjective norm, and perceived behavioral control (Ajzen, 2006).

According to this theory (Fishbein \& Ajzen, 1980), individual behavior is determined by individual attitude, social norms and perceived behavior. Based on this theory, the study postulates that consumers' purchase intention towards organic tea is influence by individual attitude towards health and environment, social norms emerging from, demographic factors such as gender, education, income level and awareness about environment and perceived behavior towards organic tea producing considering its higher price and tolerance towards it indifferent taste. After all, as this theory proposes attitude towards a behavior is determined by a cognitive structure based on accessible beliefs about the consequences of the behavior (Ajzen, 2015). Therefore, consumers are eager to pay for and consume organic tea products because they perceive these products having health benefits and also consumption of organic product also exhibits their environmental concern.

Similarly, association of organic tea products with environmental issues, wellness and health benefits also creates a perception among customers that it is much healthier, safer and more environmentally friendly than conventionally grown tea products. Likewise, SDG-12 calls for sustainable consumption and production patterns. Therefore, organic tea consumption reflects consumers concerns for health, environment and other larger social issues. Besides, producers are also playing an important role to help and support environmental protection by producing organic products that are environmentally friendly and their increasing emphasis on sustainability is gradually changing the landscape for businesses today (Tuttle \& Heap, 2008).

According to Dumea (2012) consumption patterns especially related with foods and beverages are rapidly changing nowadays. Therefore, environmental awareness and health concerns continue to influence the consumer's food purchase decision and both these factors have also 
become main motivators for consuming organic tea products. However, there are other factors such as high price, poor appearance and inconsistent taste remains as major obstacles against the consumption of organic tea products.

Regarding willingness and ability to pay for organic tea products, Rodriguez, Lupin, and Lacaze (2007) have stated that educated and affluent consumers tend to purchase more organic products as they are more exposed to health information sources and diet and they are willing to pay for organic tea product even though it is more expensive compared to non-organic tea products. However, many consumers from lower income group are unable to afford the high priced organic products. According to Radman (2005) consumers are motivated to consume in organic products is the belief that it has a superior taste as compared to non-organic products. However, the concept of taste can be highly subjective, differing from person to person.

Regarding recent studies, a study conducted on factors affecting the buying intention of organic tea consumers in Bangladesh, Sumi and Kabir (2018) have demonstrated trust and perceived price as the most affecting factors in buying intention of organic tea consumers over product attributes, health consciousness, and environmental concern. Likewise, acknowledging Indian organic market, Sakthirama (2012) argues that nowadays due to awareness of environmental degradation and related issues on food, the consumer behavior is changing towards purchase of many environmentally friendly and organic products.

Among the many organic products, organic tea is one of the consumer food products produced and consumed in India. Furthermore, in a study conducted in the context of South Korea, $\mathrm{Kim}$, and $\mathrm{Na}$ (2013) state that concern for well-being lifestyle of the organic tea drinkers and also the concern for the environmental resource have mutually affected brand preference most strongly and this was the main reason behind organic tea repurchases intentions.

Considering, these studies, in this study also, the perceived value of the customers will be measured with the effect of the perceived quality derived from the health benefit issues, environmental awareness, taste, and price, because these attributes consequently influence the buying intention of the customers. Hence, independent variables that have been applied in this study are health benefits, environmental concerns, together with taste and price. After all, M.F. Chen (2009) indicates as a customer searches for healthy lifestyle, there is positive association among health consciousness, environmental attitudes and organic products.

More importantly, these independent variables illustrate the factors that influence the dependent variable, which is consumption level of organic products. All the independent variables have been considered based on previous studies and contextual assessments and the development of specific research hypothesis have been presented below. Since, this study is exploratory in nature; these hypotheses are more akin to guidelines rather than propositions for testing.

\subsection{Conceptual Framework and Hypothesis}

In this study, purchase intention for consuming organic tea refers to consumers' willingness to purchase products and operational definition of intentions captures the motivational factors that influence purchase behavior of consumers (Ramayah, Lee, \& Mohamad, 2010), this study based on review of recent and relevant literature assumes that consumption or 
purchase intention of organic tea depends upon health benefits, environmental concerns, together with taste and price (Sumi \& Kabir, 2018; Bryła, 2016; Joshi \& Rahman, 2015). Regarding demographic factors, a study on organic products indicates significant difference in purchase intention towards organic product based on gender, females indicate significantly stronger environmental attitude and green purchase behavior than their male counterparts (Liobikienè, Grincevičienè, \& Bernatonienè, 2017). Similarly, Bieak, Kreidler, and JosephMathews (2009) indicate that education and income are strongly affecting purchase behavior towards organic product.

For conceptualizing consumer behavior for organic tea products, this study assumes that a relationship exists between various factors, purchase intention and consumer purchasing behavior (Sahney, 2011). Thus, this research examines attitude and behavior pattern of organic tea product consumption.
Antecedents
(a) Health Benefits
(b) Environmental concern
(c) Taste
(d) Price

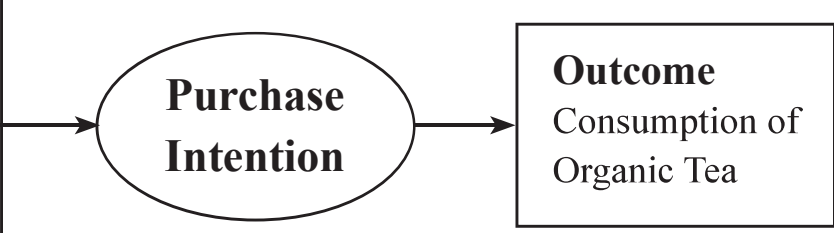

Figure 1. Relationship between health benefits, environmental concerns taste, and price, and purchase intention for consuming organic tea.

\subsubsection{Environmental Concern}

Organic farming avoids the use of synthetic chemicals such as fertilizers and pesticides by substituting them with natural manure that are safe for the health of human beings. Therefore, environment concern has directed customers toward consuming organic products.

Hypothesis (H1): Environmental concern significantly influences consumption of organic tea within consumers of Kathmandu.

\subsubsection{Health Benefit}

Health benefits have been identified as one of the major factors that influence the purchase of organic food. Hence, this study also attempts to examine positive influence of health orientation on consumption of organic tea with consumers in Kathmandu valley.

\section{Hypothesis (H2): Health concern of consumers significantly influences consumption of organic tea within Kathmandu Valley.}

\subsubsection{Price}

Because of the high price, organic food is relatively unpopular with consumers in developing countries (Demiryürek, Stopes, \& Güzel, 2008) however, in this study; this conclusion has been put under scrutiny. Besides, another study also mentions that price remains a barrier for consumption of organic product and existing gap between conventional and organic food prices needs to be reduced to increase consumption (Gil, Gracia, \& Sanchez, 2000). 
A Study on Factors Affecting Consumption of Organic Tea: Evidence from Consumers in Kathmandu Valley

Hypothesis (H3): Price of organic tea has a moderately lesser influence on consumption for the customers within Kathmandu.

\subsubsection{Taste}

Along with environmental concern and health consciousness, other specific product attributes, such as nutritional value, taste, freshness, and price (Davis, Titterington, \& Cochrane, 1995) are also perceived by consumers of organic tea products. Therefore taste, natural content, and the nutrient value of organic tea makes it a popular choice for people. However, in this study based on explorative orientations, finding of previous studies have been put under examination.

Hypothesis (H4): Taste has insignificant and indifferent influence on the consumption of organic tea.

\section{Research Design}

In this study, different dimensions of research designs have been used from the problem formulation to data analysis. Following on with Zikmund and Babin (2006), this research has also used exploratory research to explore the nature of problem. A cross-sectional quantitative method has been used for this study. Furthermore, descriptive research has been used to summarize the data gathered from consumers of organic tea in percentages, frequency, averages and distributions. Similarly, considering correlation research designs, in this study, correlation analysis has been used to understand the nature and direction of relationships between dependent and independent variables.

\subsection{Participants and Procedure}

In this study, consumers of organic tea were approached through boutiques or the tea shops selling authentic organic tea. The study has utilized different types of non-probability sampling procedures such as judgmental, snowball and convenience, to locate 50 regular organic tea consumers $(\mathrm{N}=50)$ within Kathmandu valley. Many of the boutiques and shop owners agreed to distribute the survey questionnaire to the target customers within different vicinities. For the purpose of collecting data, structured questionnaire was prepared and the questionnaire was distributed to organic tea customers with support from organic outlets and shops. And, as an emphasis, among non-probability sampling procedures, snowball sampling technique was used to effectively reach a dispersed sample within different locations of Kathmandu Valley and this process has improved the representativeness of the sample significantly. And, only those consumers with latest annual purchase intention towards organic tea were asked to respond to the survey questionnaire. The final sample of study consisted of 50 participants, with 33 female and 17 male.

Since, the study on purchase intention regarding organic tea product is a relatively new phenomenon, hence this study is exploratory in its orientation. After all, exploratory research seeks to provide new explanations that have been previously overlooked. In spite being quantitative in its methodological orientations, due to the exploratory nature of the study, this study has also adopted the interpretivism dimension to understand differences of customers 
perceptions regarding organic tea products (Saunders, Lewis, \& Thornhill, 2012) and it is also inductive in a way, when it comes to credible explaining behaviors of customers that have been observed. Together with descriptive statistics to measure of central tendency and dispersion, general respondent demographics, in this study, Pearson's correlation coefficients have been computed to examine the nature, direction and significance of the relationship between selected factors and consumption of organic tea. For the analysis of data collected from questionnaires, statistical package for social sciences (SPSS) was selected because of its ability to extensively analyze quantitative data. Besides, to examine the relationship between demographic factors, specifically gender related responses of participants concerning factors that influences purchase decision on organic tea product chi-square test has been used to analyze the data.

\subsection{Instruments and Measures}

Besides, five point Likert-type scale was used to measure variables respondents are required to rate on a scale starting from $1=$ strongly disagree, $2=$ disagree, $3=$ neutral, $4=$ agree and $5=$ strongly agree. In this study, data from columns (strongly agree/agree) were combined and also the data from columns (strongly disagree/disagree). In this study, the survey instrument consisted 20 items included a sub group of variables with independent variables-environmental concern (4 items), health benefit (4 items), price (4 items), and taste (4 items), dependent variable-purchase intention for consuming organic tea product (4 items), Cronbach's Alpha for all the items ranged from $=.76$ to .85 , and 7 items were included for questions related with demographic variable. Research instrument was developed in this study for collecting primary data from regular consumers of organic tea and the data set consists of socio-demographic factors, individual's attitudes and perceptions towards variables considered in this study.

\section{Findings}

This section of the study firstly this study deals with the demographic profile of the respondents, next descriptive analysis of the primary data collected from a questionnaire survey, and then this section covers chi-square analysis of survey response and correlation analysis of dependent and independent variables considered for this study.

\subsection{Demographic Profile of Consumers}

In this study, purposively selected 50 regular consumers $(\mathrm{N}=50)$ of organic tea consisted of approximately $66 \%$ female $(n=33)$ and $34 \%$ male consumers $(n=17)$. This indicates that female consumer buy and consume organic tea more than male consumers. Similarly, respondents in this study appear as highly educated, $50 \%$ of participants had completed their post-graduation $(n=25), 35 \%$ of participants have completed their graduation degree $(n=17)$ and $15 \%$ of participants have completed high school $(n=8)$. This indicates that consumers with higher education are also able to perceive health and environmental benefits associated with the products. Likewise, the study also finds that $10 \%$ of respondents $(n=5)$ are aged between 26-35 years, 20\% between 36-46 years $(n=10), 30 \%$ belong to $47-56(n=15)$ and $40 \%$ of them are 57 and above $(n=20)$. Hence, the majority of consumer buying organic tea products is above 35 years old and from this finding we can draw an inference that people 
above 35 tend to be more health conscious and are also aware of health benefits associated with organic tea products.

Similarly, this study indicates that homemakers $(n=20)$ and consumers involved in business activities $(n=20)$ consume organic tea. And, the remaining $(n=10)$ customers are either students or engagement in government service. Regarding monthly income, most of the consumers purchase organic tea on a monthly basis and most of consumers $(n=25,50 \%)$ on average spend about Rs. 400 or above for purchasing organic tea products. Likewise, $40 \%(n=20)$ of organic tea consumers spend within the range of 200-400 for purchasing organic tea product. Furthermore, regarding monthly income, $80 \%(n=40)$ of participants earn within the range of $50,000-70,000$ or 70,000 and above.

More importantly, demographic information regarding income and education level of organic tea customers are comparable with a study by Rodriguez, Lupin, and Lacaze (2007), which mentions educated and affluent people has regular consumers of organic products. Similarly, concerning gender differences, Laroche, Bergeron, and Barbaro-Forleo (2017) indicate in their study that females have significantly stronger purchase intention towards organic products. Demographic information is similar to study by Wier, Jensen, Andersen, and Millock (2008) that suggest the purchases of organic products are affected by age, educational level and disposable income and purchase intention towards organic products is higher among middle and upper age customers. Hence, organic marketers and retailer need to position their organic tea product acknowledging needs and wants of this demographic segment.

\subsection{Descriptive Analysis}

In this study multi-items concepts associated with selected variables were measured on a 5-point scale from 1 to 5 (here, $1=$ strongly disagree, $5=$ strongly agree). As indicated in the table-2 below, the majority of respondents in this study have positive intention to purchase organic tea based on their perceptions regarding the product. Majority of the respondents agree with the items concepts, which indicates that they perceive independent variables selected in this study as having determining influence when it comes to purchasing organic tea.

Table 2

Descriptive Analysis of Variables

\begin{tabular}{lcc}
\hline $\mathrm{N}=50$ & Weighted MEA ) & Stander Deviation \\
\hline Environment Concern & 3.50 & .71 \\
Health Benefit & 3.70 & .64 \\
Taste & 2.43 & .81 \\
Price & 2.78 & .69 \\
\hline
\end{tabular}

It is evident from the above table that the majority of respondents agree that organic tea is environment friendly. Weighted mean for environmental concern is 3.50 , which indicates environmental concern positively influences consumption of organic tea. Similarly, it is evident that majority of the respondents agree that organic tea is beneficial for health. Since, it has the highest weighted mean value; health benefits associated with organic tea appears as the most influencing factor when it comes to purchase intention regarding organic products. Likewise, 
A Study on Factors Affecting Consumption of Organic Tea: Evidence from Consumers in Kathmandu Valley

as indicated in the table, price and taste seems to have lesser influence on purchase intention of customers regarding organic tea. Customers are prepared to buy organic tea products if they perceive health benefits and environmental concern associated with the product.

\subsection{Chi-Square Analysis of Survey Response among Male and Female Respondents}

In this study, regarding health benefits, results of Pearson Chi-square indicate that female participants are significantly influenced by health benefits associated with organic tea products $(=4.86, \mathrm{df}=1, \mathrm{~N}=50, \mathrm{p}=.030)$ in comparison to male consumers. In other words, female consumers are more likely to purchase organic tea products compared to male consumers considering its health benefits. However, responses of males and females are not significantly different on whether they would purchase organic tea based on environmental concern $(=.016, \mathrm{df}=1, \mathrm{~N}=50, \mathrm{p}=.964)$.

Similarly, this study indicates regarding price, an integral part of marketing mix, male and female consumers have significantly different perception, price influences male consumer more than female consumer. In other words, male consumers are less likely to purchase organic tea considering its slightly higher price than regular tea $(=4.34, \mathrm{df}=1, \mathrm{~N}=50$, $\mathrm{p}=.022$ ). After all within the variable (willing to pay more for organic tea products than regular tea products), $65 \%$ of female respondents either strongly Agree/Agree or have remained neutral. Besides, as the data analysis also indicates that regarding taste of organic tea products, male consumers are more sensitive than female consumers.

Female consumer tends to purchase more organic products as they are more conscious toward the health of their family. After all, other studies on organic food have also indicated that female consumers are much aware than males on organic food products and they also have more awareness and stronger belief towards consumption of organic products (Dahm, Samonte, \& Shows, 2009). In overall, as this study also suggest by gender, women will be more likely to be concerned on the issues regarding to health. Besides, considering demographic segmentation of organic market, this study indicates that organic tea market needs to consider female consumers as its main target market group and develop marketing mix regarding organic tea products acknowledging their needs, wants and demands.

Table 3

Pearson Chi-Square Analysis of Survey Response

\begin{tabular}{llc}
\hline Variable $(\mathbf{N}=\mathbf{5 0})$ & $\mathbf{( C h i - S q u a r e )}$ Female $=\mathbf{3 3}$, Male $=\mathbf{1 7}$ & $\mathbf{P}$ \\
\hline Health Benefits & $=4.86,($ Female $=25 \&$ Male $=10$ Agree $)$ & $0.017^{*}$ \\
Environmental concern & $=.016,($ Male $=14 \&$ Female $=25$ Agree $)$ & 0.677 \\
Price & $=4.34,($ Female $=24 \&$ Male: 7 Agree $)$ & $.022^{*}$ \\
Taste & $=4.44,($ Female $=24 \&$ Male: 6 Agree $)$ & $0.034^{*}$ \\
\hline
\end{tabular}

$P$ Value significant at *05 levels (2-tailed) 
A Study on Factors Affecting Consumption of Organic Tea: Evidence from Consumers in Kathmandu Valley

\subsection{Correlation Analysis}

Main focus of correlation analysis is to examine the extent changes in one variable influences degree of change in the other factor. Hence, in this study to evaluate and measure the degree of association or relationship between independent and dependent variables Pearson's correlation coefficients have been computed to analyze the strength of linear relationship among them. The result shows that there is a positive relationship between consumption of organic tea as dependent variable and health benefits, environmental concerns, together with taste and price as independent variables. As the table below indicates, environmental concerns and health benefits are significantly correlated, whereas price and taste has rather moderate or even weak correlations.

\section{Table 4}

Correlation Coefficients (Pearson's r)

Correlation Statistics between Explanatory factors and Purchase intention to consume organic tea

\begin{tabular}{ll}
\hline $\mathbf{N}=\mathbf{5 0}$ Explanatory Factors & Correlations Coefficient \\
\hline Environmental Concern & $\mathrm{r}=.66^{*} \quad(\mathrm{p}=0.22<0.05)$ \\
Health Benefits & $\mathrm{r}=0.78^{*} \quad(\mathrm{p}=0.17<0.05)$ \\
Price & $\mathrm{r}=0.13 \quad(\mathrm{p}=0.164>0.05)$ \\
Taste & $\mathrm{r}=0.11 \quad(\mathrm{P}=0.276>0.05)$ \\
\hline
\end{tabular}

* Correlation is significant at the .05 level (2-tailed)

As the above table indicates Environmental concern (H1), Health Benefits (H2), Price (H3), Taste (H4) are correlated with consumption of organic tea. Concerning the strength of relationship, two independent variables environmental concern and health benefits indicate statistically significant relationship $(r(49)=0.66, p<0.05) \& r(49)=.78, p<0.05)$ with consumption of organic tea products whereas price and taste indicate weak positive correlation towards consumption of organic tea. Relationship between taste and price regarding purchase of organic tea seems rather irrelevant and indifferent.

Moreover, correlation coefficients derived in this study are comparable with findings of Durham and Andrade (2005) that main factors influencing purchase intension towards organic product consists of health and environmental concerns. Similarly, comparing demographic profile of organic tea consumers with correlation coefficients, this study also, similar to findings of Schifferstein and Ophuis (1998) argues that organic food consumers tended to be health conscious and they are willing to purchase healthier foods to improve their health and these consumers are even accept higher price when their purchase intention correlates with perceived health benefits and environment concern. Besides, organic product consumption is an environmental behavior and consumer purchase organic products because they perceive that their consumption pattern influences the environment (Krajhanzl, 2010).

Based on the nature of significance and relationship mentioned in the above table the entire hypothesis in this study has been accepted. Besides, due to the confirmed linearity of relationships between variables, there is a condition to run regression analysis in this study. 
A Study on Factors Affecting Consumption of Organic Tea: Evidence from Consumers in Kathmandu Valley

However, due to the nature of sample size and sampling procedures, predictive relationship between variables have been left out for further study, when calculated coefficient $(\beta)$ for environment concern and health benefits have revealed strong predictive association with consumption of organic tea.

\section{Discussions}

This study finds that environmental concern and consumption of organic tea are positively correlated and the relationship between these variables appears to be statistically significant, hence with this as a reference, this study argues that realizing the environmental benefits of organic tea, consumers consume organic tea. And, the finding of this study compares with Yeon and Chung (2011) that environmental consciousness positively influences consumer attitude toward buying organic products.

Similarly, this study finds that the relationship between health benefits and consumption of organic tea are both positive and highly significantly correlated. Hence, from this finding it can be inferred that most of the people consume organic tea for health benefits. More importantly finding of this study are similar with a study by Al-Taie, Rahal, AL-Sudani, and AL-Farsi (2015), as the article explores that health concerns and environmental awareness as main reasons that people consume organic products. Likewise, another study also concludes that basic motives for purchasing organic product are associated with healthiness and organic character of the product (Bryła, 2016).

Moreover, the study also observes that taste and consumption are positively correlated but co-variation appears rather weak and there is no significant relationship between these two variables on consumption, therefore this study argues that consumers of organic tea are indifference to its taste. Therefore, people consume organic tea in larger amount for its health benefits without much consideration for its taste. This finding contradicts with indication of previous study that taste is one of the main factors organic foods that consumer consider for purchase decision (Joshi \& Rahman, 2015). In addition, price and consumption of organic tea have indifferent and insignificant relationship, which means that people will still continue to consume organic tea even when prices are high or have increased. This finding is rather significant because it suggests that consumers are prepared to pay more for organic tea as compared to conventional tea products if they perceive the product they are buying as having health and environmental benefits. And, this finding also related with a study by Chang and Zepeda (2005) that concludes organic product consumers more tolerant of higher prices.

Demographic information presented in this study is also comparable with a study that finds high levels of education, income, and social class influences regular consumption of organic products (Padel \& Foster, 2005). Besides, as Chi-square analysis in this study suggests that female consumers are significant more likely to purchase organic tea acknowledging its health benefits. Similarly, a study by Laroche, Bergeron, and Barbaro-Forleo (2001) indicates that consumers are willing to pay more for environmentally friendly products and the segment of consumers were more likely to purchase organic products are females. Therefore, this study also suggests organic tea marketers, retailers and producers to develop preference-based market segmentation acknowledging health concerns and ecological awareness of customers.

NJMSR V. 3 Issue 2(2019) 25 
A Study on Factors Affecting Consumption of Organic Tea: Evidence from Consumers in Kathmandu Valley

And, the significant findings of this study are comparable with Argan (2008) that there is a statistically meaningful relationship between health care practice and the consumption of organic food, and that female respondents were more concerned about organic food than men. In addition, most of the relevant findings of this study are comparable with Basha, Mason, Shamsudin, Hussain, and Salem (2015) that purchase intention of consumers regarding organic tea is based on factors like environmental concern, health concern and lifestyle and subjective norms.

As first part of SDG 12 indicates, this study also suggests that consumers in Kathmandu Valley are prepared for responsible consumption if they perceive environmental value in any product. Customers are prepared to transact even with higher prices for organic tea products for its perceived environmental and health benefits. Besides, the study also finds that most of the consumers consume organic tea twice a day. Most of the consumers/ respondents purchased organic tea on a monthly basis and on average consumers spent above Rs. 400 on organic tea. And, as a conclusive finding in this study, health benefit is the most influencing factor when it comes to consuming organic tea in Kathmandu Valley and this finding also relates with a study by Sirieix, Kledal, and Sulitang (2011) where health has been considered as the basic reason for consumption of organic products and this finding contradicts with finding of Michaelidou \& Hassan (2008) that health consciousness is the least important motive in predicting attitudes towards organic products.

More importantly, this study finds also comparable to previous study that consumers of organic tea products have more positive attitudes toward these products, and they exhibit an increased willingness to pay higher prices for these products (Radman, 2005).Hence, this study also suggests organic tea product marketers, retailers and producers to increase consumers' knowledge about their product by effectively promoting health and environmental benefits of consuming organic tea.

Moreover, as in an article that studies association between time perspective and organic food consumption among large sample of adults, Bénard et al (2018) argue that consideration of future consequences significantly represents a psychological determinant for consumption of organic food products and the cognitive factor associated with predicting environmental and health concerns influences dietary behaviors towards organic food. Similarly, the findings of this study also indicate that concern for future when associated with environment and health positively influences a consumer to consume organic tea products. Again interpreted from the perspective of SDG-3, associated with healthy lives and well-being for people at all ages, the study explore that the consumers are prepared to substitute momentary benefits of taste and low price with future consequences of consuming organic tea, for both health and environmental benefits. Regarding implication for identifying target market and formulating marketing mix, this study suggests for organic tea producers and marketers to segment environmentally conscious consumers within the framework of attitudinal and behavioral variables (Golob \& Kronegger, 2019). After all, attitudinal variable, environmental concern and behavioral variables that include, health benefits and willingness to tolerate higher price, determine sustainable consumer segments. 
A Study on Factors Affecting Consumption of Organic Tea: Evidence from Consumers in Kathmandu Valley

\section{Conclusion \& Recommendations}

People are getting more and more conscious about the usage and the benefits of organic food and organic tea. Various factors can affect the consumption of organic tea such as environmental concern, health benefits, taste and price. Most people start their day with a cup of tea. So, the tea market has been growing tremendously within Kathmandu Valley. Various range and quality of tea are available in the market to meet the customer demand. Even there is a vast array of choices available to suit the taste of people. But the problem is that while the significance of organic tea products are being realized slowly, but surely, there is still a very small population consuming organic tea. And, this small population is convinced by the prior mentioned factors to consume organic tea.

In this study, health concern appears as most determining and pertinent. However, with the growing supply and variety of organic tea in the market, people have started to make their consumption decisions based on diverse factors; hence this study creates scope for further research regarding organic tea products. Besides, in order to promote organic and push the sales of organic tea sellers need to make health and environmental benefits of the product visible to the customers by using eco-labels highlighting health benefits effectively After all, even among young consumers health concerns resonates as the most critical factor in stimulating their purchase attitudes and intention towards organic products (Yadav \& Pathak, 2015)

This study provides valuable insight about consumer buying behavior towards organic tea products by examining the factors that influence consumers' purchase intentions. Moreover, in an article on organic consumer segmentation based on their research findings Curiel, Castro, and Quisimalín (2015) suggest that people who have heard something about organic products, later on they have more interest in consuming them. Hence, this study also recommends organic product retailers make organic tea available casually in all department stores and other small shops, which will make it more convenient for people. Promotional activities need to be carried out on a regular basis like free tea tasting and sampling of tea bag. Besides, comparable with implications suggested Azzurra, Massimiliano, and Angela (2019), this study also indicates to organic product retailers and marketers to communicate health, as well as environmental and social benefits related to the production and consumption of such food, focusing on sustainable consumer segment for sustainable consumption. There is also a need to introduce new offers such as reward cards or gift coupons to increase customers' loyalty towards organic tea. Moreover, as environmental concern positively relates to purchase intention towards eco-friendly organic products. Therefore, this study also recommends marketers of organic tea products to develop creative marketing strategies for exemplifying ecology benefits and environments values of consuming their products. After all, organic products marketers need to understand how to promote their products more effectively realizing needs and wants of environmentally conscious consumers. 


\section{References}

Al-Taie, W. A., Rahal, M. K., AL-Sudani, A. S., \& AL-Farsi, K. A. (2015). Exploring the consumption of organic foods in the United Arab Emirates. Sage Open, 5(2)

Ajzen, I. (2006). Constructing a theory of planned behavior questionnaire: Conceptual and methodological considerations. Retrieved September, 15, 2015.

Ajzen, I. (2015). Consumer attitudes and behavior: the theory of planned behavior applied to food consumption decisions. Italian Review of Agricultural Economics, 70(2), 121138.

Argan, M. (2008). The factors related to organic food consumption and healthy lifestyles: A study of Turkish consumers. SEER: Journal for Labour and Social Affairs in Eastern Europe, 11(1),121-135.

Asif, M., Xuhui, W., Nasiri, A., \& Ayyub, S. (2018). Determinant factors influencing organic food purchase intention and the moderating role of awareness: A comparative analysis. Food Quality and Preference, 63, 144-150.

Bénard, M., Baudry, J., Méjean, C., Lairon, D., Giudici, K. V., Etilé, F., \& Péneau, S. (2018). Association between time perspective and organic food consumption in a large sample of adults. Nutrition Journal, 17(1), 1.

Basha, M. B., Mason, C., Shamsudin, M. F., Hussain, H. I., \& Salem, M. A. (2015). Consumers attitude towards organic food. Procedia Economics and Finance, 31, 444-452.

Bryła, P. (2016). Organic food consumption in Poland: Motives and barriers. Appetite, 105, 737-746.

Chen, M. F. (2009). Attitude toward organic foods among Taiwanese as related to health consciousness, environmental attitudes, and the mediating effects of a healthy lifestyle. British Food Journal, 111(2), 165-178.

Chen, Y. (2011). Green organizational identity: Sources and consequence. Management Decision, 49(3), 384-404.

Curiel, J. , Castro, J. and Quisimalín, M. (2015) Organic Consumer Segmentation. Sociology Mind, 5, 176-187. doi: 10.4236/sm.2015.53016.

Dahm, M. J., Samonte, A. V., \& Shows, A. R. (2009). Organic foods: do eco-friendly attitudes predict eco-friendly behaviors?. Journal of American College Health, 58(3), 195-202.

Davis, A., Titterington, A.J., \& Cochrane, C. (1995), "Who buys organic food? A profile of the purchasers of organic food in N. Ireland", British Food Journal, 97 (10),17-23.

Demiryürek, K., Stopes, C., \& Güzel, A. (2008). Organic agriculture: The case of Turkey. Outlook on Agriculture, 37(4), 261-267. 
A Study on Factors Affecting Consumption of Organic Tea: Evidence from Consumers in Kathmandu Valley

Fishbein, M., \& Ajzen, I. (1980). Predicting and understanding consumer behavior: Attitudebehavior correspondence. Understanding Attitudes and Predicting Social Behavior, 148-172.

Gil, J. M., Gracia, A. \& Sanchez, M. (2000) Market segmentation and willingness to pay for organic products in Spain, International Food and Agribusiness Management Review, $3,207-226$

Golob, U., \& Kronegger, L. (2019). Environmental consciousness of European consumers: A segmentation-based study. Journal of Cleaner Production, 221, 1-9.

Kim, E. A., \& Na, K. S. (2013). The effects of well-being lifestyle on organic tea repurchase intention. Journal of Convergence Information Technology, 8(13), 564-589

Krajhanzl, J. (2010). Environmental and proenvironmental behavior. School and Health, 21(1), 251-274.

Laroche, M., Bergeron, J., \& Barbaro-Forleo, G. (2001). Targeting consumers who are willing to pay more for environmentally friendly products. Journal of Consumer Marketing, 18(6), 503-520.

Liobikienė, G., Grincevičienè, Š., \& Bernatonienè, J. (2017). Environmentally friendly behaviour and green purchase in Austria and Lithuania. Journal of Cleaner Production, 142, 3789-3797.

Magnusson, M.K., Arvola, A., Koivisto-Hursti, U., Aberg, 1., \& Sjoden, P. (2003). Choice of organic food is related to perceived consequences for human health and to environmental friendly behaviour. Appetite, 40, 109-117.

Michaelidou, N., \& Hassan, L. M. (2008). The role of health consciousness, food safety concern and ethical identity on attitudes and intentions towards organic food. International Journal of Consumer Studies, 32(2), 163-170.

Padel, S., \& Foster, C. (2005). Exploring the gap between attitudes and behavior: Understanding why consumers buy or do not buy organic food. British Food Journal, 107, 606-625.

Radman, M. (2005). Consumer consumption and perception of organic products in Croatia. British Food Journal, 5(107), 263-273.

Ramayah, T., Lee, J. W. C., \& Mohamad, O. (2010). Green product purchase intention: Some insights from a developing country. Resources, Conservation and Recycling, 54(12), 1419-1427.

Rodriguez, E., Lupin, B., \& Lacaze, V. (2007). Willingness to Pay for Organic Food in Argentina: Evidence from a consumer survey. International Marketing and International Trade of Quality Food Products, 1-24.

Sahney, S. (2011). Module-5 Consumer Behavior. Vinod Gupta School of Management Indian Institute of Technology Kharagpur, India, 1-17.

NJMSR V. 3 Issue 2(2019) 29 
A Study on Factors Affecting Consumption of Organic Tea: Evidence from Consumers in Kathmandu Valley

Sakthirama, V. (2012). Consumer preferences for organic tea an empirical analysis (Doctoral dissertation, Tamil Nadu Agricultural University Coimbatore)

Saunders, M., Lewis, P. \& Thornhill, A. (2012). Research methods for business students ( $^{\text {th }}$ ed.). Harlow, UK: Pearson Education.

Schifferstein, H. N., \& Ophuis, P. A. O. (1998). Health-related determinants of organic food consumption in the Netherlands. Food Quality and Preference, 9(3), 119-133.

Shafie, F. A., \& Rennie, D. (2012). Consumer perceptions towards organic food. ProcediaSocial and Behavioral Sciences, 49, 360-367.

Sirieix, L., Kledal, P. R., \& Sulitang, T. (2011). Organic food consumers' trade-offs between local or imported, conventional or organic products: a qualitative study in Shanghai. International Journal of Consumer Studies, 35(6), 670-678.

Stobelaar, D. J., Casimir, G., Borghuis, J., Marks, I., Meijer, L. and Zebeda, S. (2006) Adolescents' attitudes towards organic food: a survey of 15 to 16-year old school children. International Journal of Consumer Studies, 31, (4), 349-356.

Sumi, R., \& Kabir, G. (2018). Factors Affecting the Buying Intention of Organic Tea Consumers of Bangladesh. Journal of Open Innovation: Technology, Market, and Complexity, 4(3), 24-34.

Tuttle, T., \& Heap, J. (2008). Green productivity: moving the agenda. International Journal of Productivity and Performance Management, 4(23),455-69.

Wier, M., Jensen, K. O. D., Andersen, L. M., \& Millock, K. (2008). The character of demand in mature organic food markets: Great Britain and Denmark compared. Food Policy, $33(5), 406-421$.

Yadav, R., \& Pathak, G. (2015). Intention to purchase organic food among young consumers: Evidences from a developing nation. Appetite, 96(1), 122-128.

Yeon Kim, H., \& Chung, J. (2011). Consumer purchase intention for organic personal care products, Journal of Consumer Marketing, 28(1) 40-47.

Zikmund, W., \& Babin, B. (2006). Exploring marketing research. Cengage Learning. Bedford: Digital Press. 